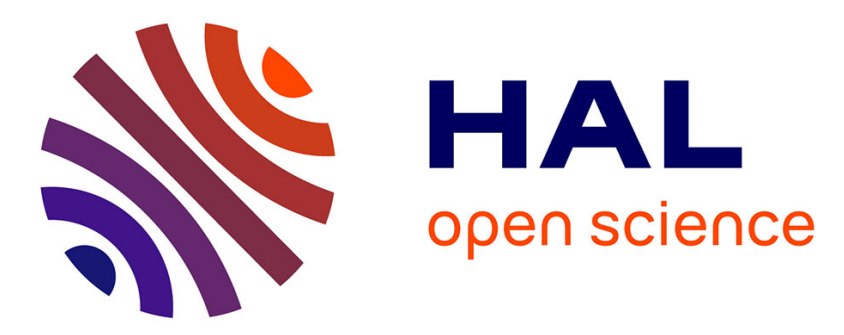

\title{
Involvement of cyclic AMP response element binding protein (CREB) and estrogen receptor phosphorylation in the synergistic activation of the estrogen receptor by estradiol and protein kinase activators.
}

\author{
Gwendal Lazennec, James P. Thomas, Benita S. Katzenellenbogen
}

\section{To cite this version:}

Gwendal Lazennec, James P. Thomas, Benita S. Katzenellenbogen. Involvement of cyclic AMP response element binding protein (CREB) and estrogen receptor phosphorylation in the synergistic activation of the estrogen receptor by estradiol and protein kinase activators.. Journal of Steroid Biochemistry and Molecular Biology, 2001, 77 (4-5), pp.193-203. inserm-00143971

\section{HAL Id: inserm-00143971 https://www.hal.inserm.fr/inserm-00143971}

Submitted on 30 Apr 2007

HAL is a multi-disciplinary open access archive for the deposit and dissemination of scientific research documents, whether they are published or not. The documents may come from teaching and research institutions in France or abroad, or from public or private research centers.
L'archive ouverte pluridisciplinaire HAL, est destinée au dépôt et à la diffusion de documents scientifiques de niveau recherche, publiés ou non, émanant des établissements d'enseignement et de recherche français ou étrangers, des laboratoires publics ou privés. 
Involvement of Cyclic AMP Response Element Binding Protein (CREB) and Estrogen Receptor Phosphorylation in the Synergistic Activation of the Estrogen Receptor by Estradiol and Protein Kinase Activators

Gwendal Lazennec ${\dagger^{*}}^{*}$, James A. Thomas II and Benita S. Katzenellenbogen It

$\dagger$ Department of Molecular and Integrative Physiology, and II Department of Cell and Structural Biology University of Illinois, Urbana, Illinois 61801

Running Title: Estrogen Receptor and PKA Crosstalk

*Present Address: INSERM U540, “Endocrinologie Moleculaire et Cellulaire des Cancers”, 60 rue de Navacelles, Montpellier, France 34090

Corresponding Author: Dr. Benita S. Katzenellenbogen

Dept of Molecular and Integrative Physiology

University of Illinois at Urbana-Champaign

524 Burrill Hall, 407 South Goodwin Ave. Urbana, IL 61801-3704

Tel: 217-333-9769 or 217-333-7838; Fax: 217-244-9906

E-mail: katzenel@life.uiuc.edu 


\begin{abstract}
Estrogen receptor (ER) and cAMP signaling pathways interact in a number of estrogen target tissues including mammary and uterine tissues. One aspect of this interaction is that estradiol and protein kinase A (PKA) activators can cooperate synergistically to activate ER-mediated transcription of both endogenous genes and reporter genes containing only estrogen response elements. The purpose of this study was to investigate the molecular mechanism of this interaction between signaling pathways. Site-directed mutagenesis of the potential PKA phosphorylation sites in the ER indicated that phosphorylation of these sites was not necessary for the observed transcriptional synergy. In transient transfection assays in two different cell lines using reporter constructs containing either cAMP response elements, estrogen response elements or both types of elements, with the addition or absence of cAMP response element binding protein (CREB) expression plasmid, we observed that only one of these cell lines exhibited estrogen/PKA transcriptional synergy. Experiments demonstrated that CREB itself was involved in the transcriptional synergy, and that transfection of CREB restored transcriptional synergy in the cell line in which it was lacking. A functional interaction between ER and CREB was also demonstrated using a mammalian cell protein interaction assay; a dominant negative mutant of CREB did not exhibit this interaction. Therefore, these data indicate that CREB protein is required for the transcriptional synergy between cAMP and estrogen signaling pathways. Furthermore, CREB cooperated with the ER on genes that did not contain cAMP response elements, but contained only estrogen response elements. We propose that activated CREB is recruited to estrogen responsive genes by an ER-coactivator complex containing proteins such as CREB binding protein $(\mathrm{CBP})$ and that the interaction of CREB with ER may assist in stabilizing its interaction with CBP and in promoting estrogen-ER and PKA transcriptional synergy.
\end{abstract}




\section{INTRODUCTION}

Protein kinase A (PKA) activators such as cholera toxin (CT) and isobutyl methylxanthine (IBMX) are potent regulators of breast cell growth in vivo and in vitro [1]. In estrogen receptor (ER)-containing breast cancer cells, we and others have shown that PKA activators enhance the transcription of estrogen regulated genes such as $\mathrm{pS} 2$, cathepsin D or progesterone receptor [2-4] and that this effect is blocked by the pure antiestrogen ICI 164,384 [2, 4]. These results are also observed in transient transfection experiments, with the magnitude of transcriptional enhancement dependent on the cellular context and gene construct used [5-9]. For example, in some cell types, PKA can act synergistically with the estradiol $\left(\mathrm{E}_{2}\right)$-occupied ER to activate transcription of estrogen response element (ERE)-containing reporter gene constructs [9]. Of particular interest is the observation that PKA activators can alter the agonist/antagonist balance of antiestrogens, conferring some agonistic activity to antiestrogens such as trans-hydroxytamoxifen (TOT) in cells in which TOT normally behaves as a pure antagonist. In addition, PKA activators reduced the inhibitory effectiveness of TOT in repressing $\mathrm{E}_{2}$-ER mediated transcription $[8,10]$. PKA activators can also transform some dominant negative ER mutants into transcriptional activators in the presence of either $E_{2}$ or antiestrogens [9].

In the classical and most simple model of action of nuclear receptors [11], the receptor is activated by its cognate ligand $[12,13]$ and binds to its specific hormone response element on its target genes. The magnitude of transcriptional activity is modulated by coactivator complexes [14, 15] and proceeds by interaction with chromatin and the pre-initiation complex [15-17]. Interaction between estrogen signaling and other nuclear receptors $[18,19]$, protein kinase $C[20]$, general transcription factors [21-23] and/or MAP kinase [24, 25] is documented, but little is known about the mechanism underlying estrogen/PKA cross-talk.

The interaction between PKA activators and ER is of particular interest since the treatment of ER-positive breast tumors often utilizes antiestrogens. In cases where PKA is unregulated and especially active, antiestrogen therapy might prove ineffective. In fact, in ER-positive breast 
cancers, only in two-third of the cases is antiestrogen treatment effective [26-28]. Hence, in certain circumstances, PKA activity might be involved in antiestrogen insensitivity as well as in the development of tamoxifen resistance. Therefore, the aim of this study is to elucidate the molecular mechanisms involved in estrogen/PKA activator synergy. Based on the observations that PKA activators can modulate the activity and also the phosphorylation state of ER [5, 29], and that $\mathrm{E}_{2}$ can increase intracellular cAMP levels in some cells [30,31], we focused on the cross-talk between these two pathways.

In this study, we investigated $\mathrm{E}_{2}$-ER/PKA synergy using two cell lines, $\mathrm{CHO}$ cells, which displayed ER transcriptional synergy with $\mathrm{E}_{2}$ and PKA, and SK-BR-3 cells, which did not exhibit this $\mathrm{E}_{2}$-ER/PKA transcriptional synergy. Because CREB is activated by PKA $[32,33]$ and since CBP (CREB binding protein) is a coactivator for both CREB and ER [34-36], we examined whether CREB was involved in the synergistic activation of ER by $E_{2}$ and PKA. We found that CREB could enhance the activity of ER in CHO cells, and that when CREB was transfected into SK-BR-3 cells, we saw transcriptional synergy where this was not seen if CREB was not transfected into these cells. These data suggest that part of the cross-talk between ER and PKA pathways involves CREB, and we propose a model to explain this whereby CREB is tethered to DNA by the ER-coactivator complex and can therefore increase transcriptional activity, even on genes lacking a cyclic AMP response element (CRE). This hypothesis has implications for the regulation of estrogen-responsive genes by estrogen and antiestrogen in breast cancer and other ER-containing cells, especially if PKA is up-regulated or overexpressed in these cells. 


\section{MATERIALS AND METHODS}

\section{Plasmids and General Reagents}

Estradiol $17 \beta\left(\mathrm{E}_{2}\right)$, cholera toxin (CT) and isobutyl methylxanthine (IBMX) were purchased from Sigma. Restriction enzymes were purchased from Life Technologies, Inc. and New England Biolabs. The plasmids 2ERE-pS2-CAT [37] and pCH110 [5] have been previously described. The vector pZT19R was kindly provided by Dr. Byron Kemper (University of Illinois, Urbana, IL) [38] and pBluescript II SK ${ }^{+}$was from Stratagene (La Jolla, CA). Plasmids were purified for transfection using either $\mathrm{CsCl}$ gradient centrifugation or a plasmid preparation kit according to manufacturer's instructions (Qiagen, Chatsworth, CA). Radioisotopes for chloroamphenicol acetyltransferase (CAT) assays and sequencing were purchased from DuPont NEN. The sequences of the oligonucleotides used for gel shift are indicated below (s: sense, as: antisense). CRE s: TGGCTGACGTCAGAGA CRE as: TCTCTGACGTCAGCCA ERE-CRE s: GATCCAGGTCACAGTGACCTCAACCCATGGCTGACGTCAGAGAG ERE-CRE as: GATCCTCTCTGACGTCAGCCAATGGGTTGAGGTCACTGTGACCTG ERE s: GATCCAGGTCACAGTGACCTGGAG ERE as: GATCCTTCAGGTCACTGTGACCTG

The VP-16 fusions to CREB and the dominant negative CREB, denoted killer CREB or KCREB, were constructed as follows. The CREB and KCREB cDNA were copied by PCR from pRSV-CREB and pRSV-KCREB, respectively. Both plasmids were kindly provided by Dr. Richard Goodman (Oregon Health Science University, Portland). The primers used were: 5' CREB primer 5'-GGAATTCATGACCATGGAATCTGGAGCC-3' and 3' CREB primer 5'CGCGTCGACATCTGATTTGTGGCAGTAAAG-3'. An EcoRI site was engineered into to 5' end and a SalI site was engineered into the $3^{\prime}$ site. This fragment was digested with EcoRI and SalI and then ligated into the vector pVP-16, which contains the VP-16 activation domain (Clontech, Palo Alto, CA). 


\section{Oligomer-Directed Mutagenesis}

The 1.8-kilobase ER-containing Bam HI fragment from pCMV5hER $\alpha$ was cloned into the BamHI site of pBluescript II SK $\mathrm{SK}^{+}$Site-directed mutagenesis was then performed according to Kunkel et al. [39], using the following oligonucleotides: S236A 5'-

GCATTTGCGGAGCCGGCATGCCTGGCATGCCTTCCTCCTGTTTTTATCAATGG-3' (gain restriction site, StuI); S305A 5'-

\section{GCCGTCAGGGACAAGGCCAACGCGTTCTTCTTAGAGCGTTTGATCATG-3' (gain} restriction site, $M l u \mathrm{I}$ ); S338A 5'-CCAGACCCTTCGCTGAGGCTTCGATGATGGGC-3' (lose restriction site, HindIII); S338E 5'-CCAGACCCTTCGAAGAGGCTTCGATGATGGGC-3' (lose restriction site, HindIII). The mutation S518A was previously described in Ekena et al. [40]. Oligonucleotides were purchased from Life Technologies, Inc. Screening for desired mutations was done by restriction analysis. Following mutagenesis, the ER cDNA clones were excised from pBluescript II SK ${ }^{+}$using BamHI and ligated into the BamHI site of pCMV5, kindly provided by Dr. David Russell (University of Texas, Dallas, TX) [41]. All ER mutations were confirmed by dideoxy sequence analysis using Sequenase 2.0 kit (U.S. Biochemical Corp./Amersham) or by the Big Dye sequencing kit (Perkin-Elmer).

\section{Cell Culture and Transfections}

Transfections were done in either Chinese hamster ovary (CHO) cells or SK-BR-3 human breast cancer cells. $\mathrm{CHO}$ cells were carried in $10 \%$ charcoal-dextran treated calf serum in DMEM/F12. SK-BR-3 cells were grown in 10\% fetal calf serum in DMEM/F12. Media was supplemented with penicillin/streptomycin and gentamycin. CHO cells and SK-BR-3 cells were plated in $60 \mathrm{~mm}$ plates in 5\% charcoal-dextran treated calf serum in DMEM/F12 and incubated for $48 \mathrm{~h}$ with $5 \% \mathrm{CO}_{2}$. Transfections were performed using $1.6 \mu \mathrm{g}$ of CAT reporter, $0.8 \mu \mathrm{g}$ internal reference $\beta$-galactosidase reporter plasmid (pCH110), 10 ng or 100 ng pCMV5hER expression vector (for CHO cells and SK-BR-3 cells respectively) and pCMV5CREB expression vector and pTZ19R plasmid DNA to a total of $8 \mu \mathrm{g}$ of DNA. Cells were incubated with calcium phosphate- 
precipitated DNA for $4 \mathrm{~h}$ and then subjected to a 1.5 min glycerol shock using $20 \%$ glycerol in Hanks' balanced salt solution (HBSS) followed by 1 min in HBSS. Fresh medium and ligands were then added. Cells were harvested $24 \mathrm{~h}$ after ligand treatment and lysed by three cycles of freezing on dry ice and thawing at $37^{\circ} \mathrm{C}$. ER transactivation activity was determined by CAT activity of the whole cell lysates and assayed as described previously [42]. CAT activity was normalized for transfection efficiency using the cotransfected internal control pCH110 $\beta$ galactosidase activity plasmid.

\section{Preparation of Nuclear Extracts}

Cells were harvested, washed in phosphate buffered saline (PBS), and resuspended in hypotonic buffer (10 mM HEPES pH 5.9, $10 \mathrm{mM} \mathrm{KCl,} \mathrm{0.1mM} \mathrm{EDTA,} \mathrm{0.1mM} \mathrm{EGTA,} \mathrm{1mM}$ DTT) containing $5 \mu \mathrm{g} / \mathrm{ml}$ aprotinin, leupeptin and pepstatin A and $0.5 \mathrm{mM}$ phenylmethylsulfonyl fluoride. After 15 min of incubation on ice, 1/16th (v/v) of NP-40 was added. The tubes were vortexed for 10 seconds and briefly spun. The supernatent containing the cytosolic proteins was discarded and the nuclei were resuspended in buffer II (20 mM HEPES pH 7.9, 0.4 M NaCl, 1 mM EDTA, 1 mM EGTA, 1 mM DTT and protease inhibitors). After 30 min incubation on ice, the cellular debris were pelleted by centrifugation at $14000 \mathrm{rpm}$ for $20 \mathrm{~min}$ in microfuge tubes.

\section{Gel Mobility Shift Assays}

Gel mobility shift assays were carried out as previously described [43]. Briefly 30,000 cpm of the ${ }^{32} \mathrm{P}$-labeled oligonucleotide was combined with $6 \mu \mathrm{g}$ of nuclear protein and $1 \mu \mathrm{g}$ poly (dI-dC) (Sigma, St. Louis, MO) in a buffer containing 20 mM HEPES, pH 7.9; 1 mM DTT; 50 mM KCl; 10\% glycerol; $2.5 \mathrm{mM} \mathrm{MgCl} 2\left(20 \mu \mathrm{l}\right.$ final volume) for $15 \mathrm{~min}$ at $4^{0} \mathrm{C} .1 \mu \mathrm{g}$ of anti-hER $\alpha \mathrm{H} 222$ (kindly provided by Dr. Geoffrey Greene, University of Chicago) or anti-CREB specific antibody were added and incubated $15 \mathrm{~min}$ at room temperature. Protein-DNA complexes were separated from the free probe by non-denaturing electrophoresis in $4 \%$ polyacrylamide gels in $0.5 \mathrm{X}$ TBE (45 mM Tris base, $45 \mathrm{mM}$ boric acid, 1 mM EDTA) at $4^{0} \mathrm{C}$. CREB antibody (specific for ATF-1 and CREB-1) was from New England Biolabs (Beverly, MA). ATF-1 (SC-243X), ATF-2 (SC-187X), ATF-3 (SC-188X), ATF-4 
(SC-244X), CREB-1 (SC-186X), CREB-2 (SC-200X) and CREM-1 (SC-440X) antibodies were from Santa Cruz Biotechnologies (Santa Cruz, CA).

\section{RESULTS}

\section{Site-directed mutagenesis of cAMP-dependent protein kinase phosphorylation sites in the human estrogen receptor}

The human $\mathrm{ER} \alpha(\mathrm{hER} \alpha)$ is known to be a phosphoprotein, and enhanced phosphorylation occurs on serine residues upon treatment with hormone or protein kinase A (PKA) activators [29, 44]. Examination of the amino acid sequence of $\mathrm{hER} \alpha$, revealed that there were four potential sites of phosphorylation by PKA (S236, S305, S338, S518). Serine 236 is in the DNA binding domain (C domain, residues 180-263), with S305, S338 and S518 being in the hormone binding domain (E domain, residues 303-553). These serines are in cAMP-dependent protein kinase phosphorylation sequences XRRXSX or SKKXSX.

These serines were mutated to alanine either separately, or in some cases together, to determine whether the synergistic enhancement of transcription by estradiol and the PKC activator cholera toxin/IBMX was dependent on these residues. The mutant receptors were transiently transfected into Chinese hamster ovary $(\mathrm{CHO})$ cells along with an estrogen-responsive 2ERE-pS2CAT reporter, which contains two consensus EREs upstream of the promoter from $\mathrm{pS} 2$, which is an estrogen regulated gene. As can be seen in Figure 1, none of these mutations had an effect on receptor transcriptional activity. All of the mutants showed response to estradiol $\left(10^{-10} \mathrm{M}\right)$ of a magnitude similar to that of the wild type (wt) ER, and all showed enhancement of transcriptional activity in the presence of $E_{2}$ and PKA activator. Even when the serine at 338 was mutated to a glutamate (S338E) to mimic the acidic charge of a phospho group, activity similar to wild type ER was observed. These findings indicate that phosphorylation at these sites is not essential for the estradiol/PKA activator synergy observed in these cells. 


\section{CHO cells and SK-BR-3 cells respond in a different manner to PKA activators}

Based on the lack of effect of the phosphorylation site ER mutagenesis experiments, we hypothesized that other proteins activated by PKA might be involved in the $\mathrm{E}_{2} / \mathrm{PKA}$ transcriptional synergy. We examined the role of CREB, not only because it is activated by PKA, but because it shares a common coactivator with the ER [36]. To this end, we constructed several different reporter constructs with the $\mathrm{pS} 2$ minimal promoter and controlled by EREs or CREs, either alone or together. These reporter constructs were tested in CHO cells and in SK-BR-3 breast cancer cells, both of which are ER-negative cells.

In $\mathrm{CHO}$ cells (Fig. 2A), activity on the 2ERE-pS2-CAT reporter was dependent on the presence of transfected $\mathrm{ER}$ and the response to $\mathrm{E}_{2}+\mathrm{CT} / \mathrm{IBMX}$ was markedly greater than that in the presence of $\mathrm{E}_{2}$ alone. The cAMP response element (CRE) activity (CRE-pS2-CAT) was stimulated by CT/IBMX in the absence or presence of transfected ER, but this activity was higher with cotransfection of ER. CRE activity in the presence of CT/IBMX was not enhanced with $\mathrm{E}_{2}+$ CT/IBMX stimulation and both were about 3-fold higher than the stimulation in the absence of ER. This may reflect the finding that CREB phosphorylation can be regulated by $E_{2}$ [45]. As would be predicted, the reporter 2(ERE-CRE)-pS2-CAT displayed higher activity than either CRE or ERE construct alone. ER increased the response seen on all three reporter constructs; however, the CRE was still only inducible by CT/IBMX. The transcriptional synergy between $\mathrm{E}_{2}$ and CT/IBMX was seen on both the 2ERE-pS2-CAT and 2(ERE-CRE)-pS2-CAT reporter genes.

In SK-BR-3 cells (Fig. 2B), a different pattern of response was observed. The CRE construct was inactive even when cells were treated with CT/IBMX and this activity changed little with the addition of ER to the cells. A transcriptional synergy was observed on the 2(ERE-CRE)pS2-CAT reporter, as in the CHO cells. However, no synergy was seen on the 2ERE-pS2-CAT reporter, unlike what is seen in $\mathrm{CHO}$ cells. Therefore, we decided that since these two cell lines displayed differences in the estradiol/PKA activator transcriptional synergy on the ERE-containing 
reporter gene, they would be worthwhile to use in examining the phenomenon of transcriptional synergy.

\section{Assessment of the involvement of CREB in ER transcriptional activity}

To determine if CREB was involved in the different responses observed in $\mathrm{CHO}$ and SKBR-3 cells, we transfected a human CREB expression plasmid into these cells. In CHO cells (Fig. 3), CREB enhanced the transcriptional response evoked by $\mathrm{E}_{2}+\mathrm{CT} / \mathrm{IBMX}$ on the three different gene constructs. The enhancement by CREB was dramatic on all 3 constructs. The stimulation was reduced at the highest level of transfected CREB, presumably due to squelching, but it was still higher than without CREB (empty CMV5 vector). In contrast, a dominant negative mutant of CREB called KCREB, for Killer CREB [46], was much less effective and did not achieve the levels of induction seen with wild type CREB.

When CREB was expressed in SK-BR-3 cells (Fig. 4), a very interesting result was observed. On the 2ERE-pS2-CAT reporter, where synergy was not observed with $\mathrm{E}_{2}$ and CT/IBMX with ER alone (cf. Fig. 2B), addition of CREB now resulted in transcriptional synergy between $\mathrm{E}_{2}$ and CT/IBMX. On the 2(ERE-CRE)-pS2-CAT reporter, where synergy was observed with $\mathrm{E}_{2}$ plus CT/IBMX with ER alone (cf. Fig. 2B), synergistic activity was still observed with ER and added CREB but the levels of CAT activity were somewhat reduced upon addition of CREB. This may be due to the fact that activation without added CREB was already about at the maximum because of saturation of essential coactivators.

\section{Examination of CREB isoforms present in CHO cells and SK-BR-3 cells}

Because of the differences in activation on CREs in CHO cells and SK-BR-3 cells, gel shift experiments were performed using nuclear extracts from both cell lines. In CHO cells (Fig. 5A), the major isoforms of CREB present that bound to a radiolabeled CRE oligo probe were CREB1 and CREM1. This was also the case in SK-BR-3 cells (Fig. 5B). Interestingly, in the SK-BR-3 
cells, a lower band was also seen, but this could not be shifted with CREB antibodies. Thus the expression of CREB isoforms in both cell lines appeared to be similar and did not appear to account for the differences in transcriptional activity seen on the CRE-pS2-CAT reporter.

\section{CREB interacts with ER on an ERE}

Because transfected CREB could enhance transcription in both cell lines as well as restore synergistic transcription on the 2ERE reporter in SK-BR-3 cells, we examined whether ER and CREB could interact. We could not detect any interaction between these proteins in immunoprecipitation experiments (data not shown). Neither could we detect any interaction in gel super-shift assays using ER and CREB antibodies and radiolabeled CRE or ERE oligomers (data not shown). Since these assays would be unlikely to detect indirect or weak interactions, we performed experiments using a modified mammalian two-hybrid system in intact cells, where full length ER was used to bind to a 1ERE-pS2-CAT reporter and various CREB-VP16 constructs were tested (Fig. 6). As can be seen in this experiment, full length wild type CREB could interact with the ER on this reporter (ER plus VP16:CREB). Note that this gene construct, containing only 1 ERE, does not show any estradiol mediated activation of the estrogen receptor (ER + VP-16). By contrast, KCREB, a dominant negative version of CREB that is deficient in DNA binding [46], did not show any interaction in this protein interaction system. 


\section{DISCUSSION}

Transcriptional synergy between ER and PKA activators on ERE regulated genes is well documented in both long-term cultured cells and primary cultured estrogen target cells [5-8]. Our experiments reveal that the protein CREB is involved in this synergy. Although the ER is a phosphoprotein $[29,30]$, our data suggest that it may not be directly phosphorylated by PKA since elimination of potential PKA phosphorylation sites did not reduce the transcriptional activity of ER in response to $\mathrm{E}_{2}$ and PKA activators. Because it was possible that PKA was activating other proteins that interacted with the ER, we examined the role of CREB, a protein known to be phosphorylated by PKA $[4,47,48]$, which also shares a common coactivator with ER, namely CBP $[34,35]$.

CREB is a transcription factor that binds to a CRE, which consists of the motif, 5'TGACGTCA-3' (for review [49]). Numerous CREB-related proteins have been identified including CREB-1, CREB-2, ATF-1, ATF-2, ATF-3, ATF-4 and CREM1 [49]. CREB is part of the family of bZIP transcription factors, which have a basic activation region and a leucine zipper dimerization domain [49]. In the amino terminal region of CREB is a region called KID (kinase inducible domain) or $\mathrm{P}$ box. This contains a large proportion of acidic residues [29, 47, 50], as well as a serine at position 133 which is the target of PKA [47]. This phosphorylation is thought to alter the conformation of the transactivation domain which presents the glutamine rich regions for interaction with the pre-initiation complex [51]. CREB is able to dimerize with CREM or ATF1, but there is also possible heterodimerization of ATF members with c-fos, c-jun or C/EBP [29, 52]. It has been shown that CREB could act synergistically with nuclear receptors such as SF-1 [53].

To examine the possibility of CREB and ER interaction, we used two cell lines which displayed different responses to PKA activators and estrogen: $\mathrm{CHO}$ cells, which exhibited transcriptional synergy, and SK-BR-3 cells, which did not exhibit the synergy. We also used several different reporter constructs that had EREs exclusively or a combination of EREs and 
CREs. Experiments using the reporter gene constructs and the two cell lines gave results which indicated that CREB was involved in mediating the PKA-ER synergy.

Transfection of CREB expression vector into $\mathrm{CHO}$ cells enhanced the transcriptional activity of ER on gene constructs containing only a CRE, or only EREs, or combined CREs and EREs (Fig. 3). Most interestingly, in SK-BR-3 cells transcriptional synergy on the 2ERE reporter was observed only when additional CREB was provided to the cells. In contrast, in SK-BR-3 cells, the reporter containing combined CREs and EREs did show transcriptional synergy, even without transfected CREB, which was expected since endogenous CREB can bind directly to the CRE DNA. This supports the contention that the mechanism of transcriptional synergy is different on the ERE versus the combined CRE-ERE constructs examined. Although the response of CHO and SK-BR-3 cells was different with respect to CT/IBMX, we could not detect any differences in the expression of endogenous CREB proteins to account for the differences in transcriptional response as both cell types appeared to express the same isoforms of CREB.

We tried to test for a direct interaction between ER and CREB using several different techniques for detecting protein-protein interactions, but it was only in the in vivo mammalian interaction assay that we observed interaction. This leads us to believe that the interaction is not direct, but is mediated by coactivator proteins such as CBP and SRC-1 or other SRC family members. SRC-1 is a steroid receptor coactivator and CBP is a common coactivator for both ER and CREB. It has been shown that CBP and SRC-1 interaction results in synergistic enhancement of ER transcriptional activity upon estradiol occupancy of the receptor $[54,55]$. Based on our results comparing the findings in CHO cells and SK-BR-3 cells, and the observations reported by others about CBP and SRC-1, we propose a model to explain the PKA/ER transcriptional synergy (Fig. 7).

One can imagine several different scenarios of gene activation by the ER and CREB. If the gene promoter contains both EREs and CREs, the transcriptional synergy is likely the result of numerous activator proteins binding the promoter region [56]. However, what we see in these 
experiments is a transcriptional synergy on reporter genes containing only EREs where CREB cannot bind to these DNA sites. Thus we hypothesize that CREB can be recruited to the ERcoactivator complex by being tethered via ER and certain coactivators such as CBP (Fig. 7). This would result in greater transcription of the gene, even though CREB does not bind to the ERE DNA directly. Such a mechanism is documented in a reciprocal sense for activation of AP-1 enhancer elements by ER, where the ER does not bind the DNA [21]. To test this hypothesis, a dominant negative mutant form of CREB, KCREB, was tested in the mammalian cell protein interaction system, and the KCREB did not show any interaction with ER.

In the model presented in Fig. 7, in CHO cells (panel A), we see that the CRE is active and that we can observe transcriptional synergy between CREB and ER on promoters containing only EREs. The addition of CREB expression vector did not change the nature of the responses, but only their magnitude. However, in SK-BR-3 cells (panel B), we observed that a CRE was inactive and we did not see any transcriptional synergy between CREB and ER on a reporter containing only EREs. The addition of exogenous CREB however resulted in weak activity on CREs, but more importantly, it resulted in transcriptional synergy on reporters containing only EREs. Thus, the overexpressed CREB did change the nature of the transcriptional response. Based on the mammalian protein interaction assay and the lack of interaction in GST pulldowns and gel-shift assays, it is likely that the interaction of CREB and ER is indirect, mediated through other coactivator proteins such as SRC-1 and CBP. CBP is a coactivator for both CREB and ER, and these domains of interaction are distinct, which would allow for both transcription factors to bind. In addition, the coactivator SRC-1 binds both ER and CBP, so it could also be involved in the interaction. Our model proposes that CREB is being recruited to the ERE by the ER-SRC-CBP complex, which means that CREB does not need to bind the DNA to modulate the transcriptional activity. This is the reverse of the case in the activation of the ovalbumin gene by ER through the AP-1 activator complex, where ER does not bind DNA [27]. In our observations, the coactivators serve as adaptors connecting two distinct activators which 
facilitate the response of PKA signaling on estrogen regulated reporter genes without cAMP response elements. Thus, genes that are estrogen responsive could also be PKA responsive genes in an estrogen-dependent mechanism.

This model could account for differences in the agonist/antagonist activities of selective estrogen receptor modulators (SERMs) [57], as well as the effectiveness of estradiol, in different target tissues including breast cancer. If there are elevated levels of CREB, or if PKA is upregulated or constitutively active, one could see enhanced ER mediated transcription with $\mathrm{E}_{2}$ or SERMs such as tamoxifen. Indeed, in MCF-7 breast cancer cells cotreated with tamoxifen and CT/IBMX, we see enhancement of tamoxifen agonism and ER-mediated transcription at EREcontaining gene sites by CT/IBMX as is observed with $\mathrm{E}_{2}$ and CT/IBMX [8]. The data presented in this study demonstrate the importance of CREB in the crosstalk between estrogen, ER, and the PKA pathway. That CREB can interact with the ER, resulting in strong transcriptional activity on reporters that do not have DNA binding sites for CREB, implies that CREB transcriptional regulation is not limited to genes containing CREs, but could encompass estrogen regulated genes in ER-containing target cells.

\section{ACKNOWLEDGEMENTS}

We are grateful for the support of this research by grants from the NIH to Benita S. Katzenellenbogen (CA18119 and CA60514). James A. Thomas received partial support from NIH 5T32 GM07283. 


\section{REFERENCES}

[1] L.G. Sheffield, C.W. Welsch, Cholera-toxin-enhanced growth of human breast cancer cell lines in vitro and in vivo: interaction with estrogen, Int. J. Cancer 36 (1985) 479-483.

[2] S.M. Aronica, B.S. Katzenellenbogen, Progesterone receptor regulation in uterine cells: stimulation by estrogen, cyclic adenosine 3',5'-monophosphate, and insulin-like growth factor I and suppression by antiestrogens and protein kinase inhibitors, Endocrinology 128 (1991) 2045-2052.

[3] D. Chalbos, A. Philips, F. Galtier, H. Rochefort, Synthetic antiestrogens modulate induction of pS2 and cathepsin-D messenger ribonucleic acid by growth factors and adenosine 3',5'monophosphate in MCF7 cells, Endocrinology 133 (1993) 571-576.

[4] M. El Tanani, C.D. Green, Interaction between estradiol and cAMP in the regulation of specific gene expression, Mol. Cell. Endocrinol. 124 (1996) 71-77.

[5] S.M. Aronica, B.S. Katzenellenbogen, Stimulation of estrogen receptor-mediated transcription and alteration in the phosphorylation state of the rat uterine estrogen receptor by estrogen, cyclic adenosine monophosphate, and insulin-like growth factor-I, Mol. Endocrinol. 7 (1993) 743 752.

[6] H. Cho, B.S. Katzenellenbogen, Synergistic activation of estrogen receptor-mediated transcription by estradiol and protein kinase activators, Mol. Endocrinol. 7 (1993) 441-452.

[7] M. El Tanani, C.D. Green, Two separate mechanisms for ligand-independent activation of the estrogen receptor, Mol. Endocrinol. 11 (1997) 928-937.

[8] N. Fujimoto, B.S. Katzenellenbogen, Alteration in the agonist/antagonist balance of antiestrogens by activation of protein kinase A signaling pathways in breast cancer cells: antiestrogen selectivity and promoter dependence, Mol. Endocrinol. 8 (1994) 296-304.

[9] B.A. Ince, M.M. Montano, B.S. Katzenellenbogen, Activation of transcriptionally inactive human estrogen receptors by cyclic adenosine 3',5'-monophosphate and ligands including antiestrogens, Mol. Endocrinol. 8 (1994) 1397-1406. 
[10] F. Pakdel, B.S. Katzenellenbogen, Human estrogen receptor mutants with altered estrogen and antiestrogen ligand discrimination, J. Biol. Chem. 267 (1992) 3429-3437.

[11] R.M. Evans, The steroid and thyroid hormone receptor superfamily, Science 240 (1988) 889895.

[12] P.S. Danielan, R. White, J.A. Lees, M.G. Parker, Identification of a conserved region required for hormone-dependent transcriptional activation by steroid hormone receptors, EMBO J. 11 (1991) 1025-1033.

[13] D. Metzger, S. Ali, J.M. Bornert, P. Chambon, Characterization of the amino-terminal transcriptional activation function of the human estrogen receptor in animal and yeast cells, J. Biol. Chem. 270 (1995) 9535-9542.

[14] C.K. Glass, D.W. Rose, M.G. Rosenfeld, Nuclear receptor coactivators, Curr. Opin. Cell Biol. 9 (1997) 222-232.

[15] G. Lazennec, T.R. Ediger, L.N. Petz, A.M. Nardulli, B.S. Katzenellenbogen, Mechanistic aspects of estrogen receptor activation probed with constitutively active estrogen receptors correlations with DNA and coregulator interactions and receptor conformational changes, Mol. Endocrinol. 11 (1997) 1375-1386.

[16] J.C.G. Blanco, I.M. Wang, S.Y. Tsai, M.J. Tsai, B.W. O'Malley, P.W. Jurutka, M.R. Haussler, K. Ozato, Transcription factor TFIIB and the vitamin D receptor cooperatively activate ligand-dependent transcription, Proc. Natl. Acad. Sci. USA 92 (1995) 1535-1539.

[17] C. Brou, J. Wu, S. Ali, E. Scheer, C. Lang, I. Davidson, P. Chambon, L. Tora, Different TBP-associated factors are required for mediating the stimulation of transcription in vitro by the acidic transactivator GAL-VP16 and the two nonacidic activation functions of the estrogen receptor, Nucl. Acids Res. 21 (1993) 5-12.

[18] G. Lazennec, L. Kern, Y. Valotaire, G. Salbert, The nuclear orphan receptors COUP-TF and ARP-1 positively regulate the trout estrogen receptor gene through enhancing autoregulation, Mol. Cell. Biol. 17 (1997) 5053-5066. 
[19] Y. Ledrean, D. Liu, A. Wong, F. Xiong, C.L. Hew, Steroidogenic factor 1 and estradiol receptor act in synergism to regulate the expression of the salmon gonadotropin ii-beta subunit gene, Mol. Endocrinol. 10 (1996) 217-229.

[20] D.M. Ignar-Trowbridge, M. Pimentel, M.G. Parker, J.A. McLachlan, K.S. Korach, Peptide growth factor cross-talk with the estrogen receptor requires the $\mathrm{A} / \mathrm{B}$ domain and occurs independently of protein kinase C or estradiol, Endocrinology 137 (1996) 1735-1744.

[21] M.P. Gaub, M. Bellard, I. Scheuer, P. Chambon, P. Sassone-Corsi, Activation of the ovalbumin gene by the estrogen receptor involves the fos-jun complex, Cell 63 (1990) 12671276.

[22] J.N. Miner, K.R. Yamamoto, The basic region of AP-1 specifies glucocorticoid receptor activity at a composite response element, Genes Dev 6 (1992) 2491-2501.

[23] R. Schüle, M. Muller, C. Kaltschmidt, R. Renkawitz, Many transcription factors interact synergistically with steroid receptors, Science 242 (1988) 1418-1420.

[24] G. Bunone, P.A. Briand, R.J. Miksicek, D. Picard, Activation of the unliganded estrogen receptor by EGF involves the MAP kinase pathway and direct phosphorylation, EMBO J. 15 (1996) 2174-2183.

[25] S. Kato, H. Endoh, Y. Masuhiro, T. Kitamoto, S. Uchiyama, H. Sasaki, S. Masushige, Y. Gotoh, E. Nishida, H. Kawashima, et al., Activation of the estrogen receptor through phosphorylation by mitogen- activated protein kinase, Science 270 (1995) 1491-1494.

[26] V.C. Jordan, C.S. Murphy, Endocrine pharmacology of antiestrogens as antitumor agents, Endocr. Rev. 11 (1990) 578-610.

[27] B.S. Katzenellenbogen, M.M. Montano, K. Ekena, M.E. Herman, E.M. McInerney, Antiestrogens: Mechanisms of action and resistance in breast cancer, Breast Cancer Res. Treat. 44 (1997) 23-38.

[28] R. Santen, A. Manni, H. Harvey, C. Redmond, Endocrine treatment of breast cancer in women, Endocr. Rev. 11 (1990) 221-265. 
[29] P. Le Goff, M.M. Montano, D.J. Schodin, B.S. Katzenellenbogen, Phosphorylation of the human estrogen receptor, J. Biol. Chem. 269 (1994) 4458-4466.

[30] S.M. Aronica, W.L. Kraus, B.S. Katzenellenbogen, Estrogen action via the cAMP signaling pathway: stimulation of adenylate cyclase and cAMP-regulated gene transcription, Proc. Natl. Acad. Sci. USA 91 (1994) 8517-8521.

[31] M.Y. Farhat, Y.S. Abi, B. Dingaan, R. Vargas, P.W. Ramwell, Estradiol increases cyclic adenosine monophosphate in rat pulmonary vascular smooth muscle cells by a nongenomic mechanism, J. Pharmacol. Exper. Therapeut. 276 (1996) 652-657.

[32] P.K. Dash, K.A. Karl, M.A. Colicos, R. Prywes, E.R. Kandel, cAMP response elementbinding protein is activated by $\mathrm{Ca} 2+/$ calmodulin- as well as cAMP-dependent protein kinase, Proc. Natl. Acad. Sci. U S A 88 (1991) 5061-5065.

[33] M. Sheng, M.A. Thompson, M.E. Greenberg, CREB: a Ca(2+)-regulated transcription factor phosphorylated by calmodulin-dependent kinases, Science 252 (1991) 1427-1430.

[34] D. Chakravarti, V.J. Lamorte, M.C. Nelson, T. Nakajima, I.G. Schulman, H. Juguilon, M. Montminy, R.M. Evans, Role of CBP/p300 in nuclear receptor signalling, Nature 383 (1996) 99-103.

[35] B. Hanstein, R. Eckner, J. DiRenzo, S. Halachmi, H. Liu, B. Searcy, R. Kurokawa, M. Brown, p300 is a component of an estrogen receptor coactivator complex, Proc. Natl. Acad. Sci. U S A 93 (1996) 11540-11545.

[36] Y. Kamei, L. Xu, T. Heinzel, J. Torchia, R. Kurokawa, B. Gloss, S.C. Lin, R.A. Heyman, D.W. Rose, C.K. Glass, M.G. Rosenfeld, A CBP integrator complex mediates transcriptional activation and AP-1 inhibition by nuclear receptors, Cell 85 (1996) 403-414.

[37] M.M. Montano, K. Ekena, K.D. Krueger, A.L. Keller, B.S. Katzenellenbogen, Human estrogen receptor ligand activity inversion mutants: receptors that interpret antiestrogens as estrogens and estrogens as antiestrogens and discriminate among different antiestrogens, Mol. Endocrinol. 10 (1996) 230-242. 
[38] D.A. Mead, E. Szczesna-Skorupa, B. Kemper, Single-stranded DNA 'blue' T7 promoter plasmids: a versatile tandem promoter system for cloning and protein engineering, Protein Eng. 1 (1986) 67-74.

[39] T.A. Kunkel, J.D. Roberts, R.A. Zakour, Rapid and efficient site-specific mutagenesis without phenotypic selection, Methods Enzymol. 154 (1987) 367-382.

[40] K. Ekena, K.E. Weis, J.A. Katzenellenbogen, B.S. Katzenellenbogen, Identification of amino acids in the hormone binding domain of the human estrogen receptor important in estrogen binding, J. Biol. Chem. 271 (1996) 20053-20059.

[41] S. Andersson, D.N. Davis, H. Dahlback, H. Jornvall, D.W. Russell, Cloning, structure, and expression of the mitochondrial cytochrome P-450 sterol 26-hydroxylase, a bile acid biosynthetic enzyme., J. Biol. Chem. 264 (1988) 8222-8229.

[42] J.C. Reese, B.S. Katzenellenbogen, Mutagenesis of cysteines in the hormone binding domain of the human estrogen receptor. Alterations in binding and transcriptional activation by covalently and reversibly attaching ligands, J. Biol. Chem. 266 (1991) 10880-10887.

[43] G. Lazennec, L. Kern, G. Salbert, D. Saligaut, Y. Valotaire, Cooperation between the human estrogen receptor (ER) and MCF-7 cell- specific transcription factors elicits high activity of an estrogen- inducible enhancer from the trout ER gene promoter, Mol. Endocrinol. 10 (1996) 1116-1126.

[44] R.R. Denton, N.J. Koszewski, A.C. Notides, Estrogen receptor phosphorylation. Hormonal dependence and consequence on specific DNA binding, J. Biol. Chem. 267 (1992) 7263-7268.

[45] Y. Zhou, J.J. Watters, D.M. Dorsa, Estrogen rapidly induces the phosphorylation of the cAMP response element binding protein in rat brain, Endocrinology 137 (1996) 2163-2166.

[46] K.M. Walton, R.P. Rehfuss, J.C. Chrivia, J.E. Lochner, R.H. Goodman, A dominant repressor of cyclic adenosine 3',5'-monophosphate (cAMP)- regulated enhancer-binding protein activity inhibits the cAMP-mediated induction of the somatostatin promoter in vivo, Mol. Endocrinol. 6 (1992) 647-655. 
[47] G.A. Gonzalez, M.R. Montminy, Cyclic AMP stimulates somatostatin gene transcription by phosphorylation of CREB at serine 133, Cell 59 (1989) 675-680.

[48] K.K. Yamamoto, G.A. Gonzalez, P. Menzel, J. Rivier, M.R. Montminy, Characterization of a bipartite activator domain in transcription factor CREB, Cell 60 (1990) 611-617.

[49] T.E. Meyer, J.F. Habener, Cyclic adenosine 3',5'-monophosphate response element binding protein (CREB) and related transcription-activating deoxyribonucleic acid- binding proteins, Endocr. Rev. 14 (1993) 269-290.

[50] G.A. Gonzalez, P. Menzel, J. Leonard, W.H. Fischer, M.R. Montminy, Characterization of motifs which are critical for activity of the cyclic AMP-responsive transcription factor CREB, Mol. Cell. Biol. 11 (1991) 1306-1312.

[51] M. Horikoshi, T. Hai, Y.S. Lin, M.R. Green, R.G. Roeder, Transcription factor ATF interacts with the TATA factor to facilitate establishment of a preinitiation complex, Cell 54 (1988) 1033-1042.

[52] T. Hai, T. Curran, Cross-family dimerization of transcription factors Fos/Jun and ATF/CREB alters DNA binding specificity, Proc. Natl. Acad. Sci. U S A 88 (1991) 3720-3724.

[53] D.L. Carlone, J.S. Richards, Functional interactions, phosphorylation, and levels of 3',5'cyclic adenosine monophosphate-regulatory element binding protein and steroidogenic factor-1 mediate hormone-regulated and constitutive expression of aromatase in gonadal cells, Mol. Endocrinol. 11 (1997) 292-304.

[54] C.L. Smith, S.A. Onate, M.J. Tsai, B.W. O'Malley, CREB binding protein acts synergistically with steroid receptor coactivator-1 to enhance steroid receptor-dependent transcription, Proc. Natl. Acad. Sci. U S A 93 (1996) 8884-8888.

[55] T.P. Yao, G. Ku, N. Zhou, R. Scully, D.M. Livingston, The nuclear hormone receptor coactivator SRC-1 is a specific target of p300, Proc. Natl. Acad. Sci. U S A 93 (1996) 1062610631. 
[56] T. Chi, P. Lieberman, K. Ellwood, M. Carey, A general mechanism for transcriptional synergy by eukaryotic activators, Nature 377 (1995) 254-257.

[57] B.S. Katzenellenbogen, M.M. Montano, T.R. Ediger, J. Sun, K. Ekena, G. Lazennec, P.G.V. Martini, E.M. McInerney, R. Delage-Mourroux, K. Weis, J.A. Katzenellenbogen, Estrogen receptors: selective ligands, partners, and distinctive pharmacology, Rec. Prog. Hormone Res. 55 (2000) 163-195. 


\section{FIGURE LEGENDS}

Fig. 1. Effect of mutation of potential protein kinase A (PKA) phosphorylation sites of human ER $\alpha$ on ER transcriptional activity in response to estradiol $\left(E_{2}\right)$ and PKA activators. Wild type (wt) and mutant ERs were tested for their ability to respond to $\mathrm{E}_{2}$ and PKA activators (CT and IBMX) in CHO cells using the 2ERE-TATA-CAT reporter. 0.1 $\mathrm{nM} 17 \beta$-estradiol, $1 \mu \mathrm{g} / \mathrm{ml}$ cholera toxin and $0.1 \mathrm{mM}$ IBMX were used. Results are expressed as the percent of activity of wild type human ER with $0.1 \mathrm{nME}_{2}$. Values are the mean +/- SD from three experiments.

Fig. 2. Synergy between $\mathrm{E}_{2}$ and $\mathrm{CT} / \mathrm{IB} M \mathrm{MX}$ is detectable in $\mathrm{CHO}$ cells but not in SK-BR-3 cells. (A) CHO cells were transfected with different reporters with or without ER expression vector. Error bars represent the mean $+/-\mathrm{SD}$ of at least three experiments. (B) Same experiments, but in SK-BR-3 cells. For some values, error bars are too small to be seen.

Fig. 3. Wild type CREB can effectively enhance synergism between $E_{2}$ and PKA activators in CHO cells. CHO cells were transfected with the indicated reporters along with empty pCMV5, pCMV5:CREB or pCMV5:KCREB. The amount of expression vector used was adjusted with pCMV5 vector. Cells were treated with either control ethanol vehicle or $\mathrm{E}_{2}$ plus CT/IBMX. Results are expressed in fold induction, that is the ratio of the activity detected in the presence of $E_{2}$ plus CT/IBMX divided by the activity of the same construct in the presence of control ethanol vehicle. Error bars represent the mean $+/-\mathrm{SD}$ of four or more experiments. For some values, error bars are too small to be seen.

Fig. 4. Expression of CREB in SK-BR-3 cells results in synergy between $E_{2}$ and PKA activators. SK-BR-3 cells were transfected with indicated reporter constructs and pCMV:hER or pCMV5:CREB (500 ng) alone or in combination. Cells were treated with control 
ethanol vehicle, $0.1 \mathrm{nM} \mathrm{E}_{2}, 1 \mu \mathrm{g} / \mathrm{ml}$ cholera toxin (CT) and $0.1 \mathrm{mM}$ IBMX, or both $\mathrm{E}_{2}$ and CT/IBMX. Error bars represent the mean +/- SD of six or more experiments.

Fig. 5. Of the CREB family proteins, CHO and SK-BR-3 cells show predominant interaction of endogenous CREB 1 and CREM 1 with CRE oligonucleotide. Gel shift experiments were performed on the CRE probe using (A) CHO or (B) SK-BR-3 nuclear extracts. To assess the identity of the proteins bound to the radiolabeled CRE, specific antibodies for CREB-1, CREB-2, ATF-1, ATF-2, ATF-3, ATF-4 or CREB-1 were used. The CREB antibody (lane 2) recognizes both CREB-1 and ATF-1. SSB, super-shifted band; SB, shifted band; LB, lower band.

Fig. 6. Functional interaction between CREB and ER is detected in a mammalian two-hybrid transcription system. SK-BR-3 cells were transfected with the 1ERE-pS2-CAT reporter construct, human ER expression vector and $1 \mu \mathrm{g}$ of pVP16, pVP16-CREB, or pVP16-KCREB constructs as indicated. Interaction was monitored as fold induction in CAT activity. CAT activity was the same in cells treated with $0.1 \mathrm{nM} \mathrm{E}_{2}$ or with control $0.1 \%$ ethanol vehicle. For some values, error bars are too small to be seen.

Fig. 7. Proposed model for the interaction between ER and CREB that results in transcriptional synergy at estrogen response element-containing gene sites in the presence of estradiol and PKA activators. See text for details. 


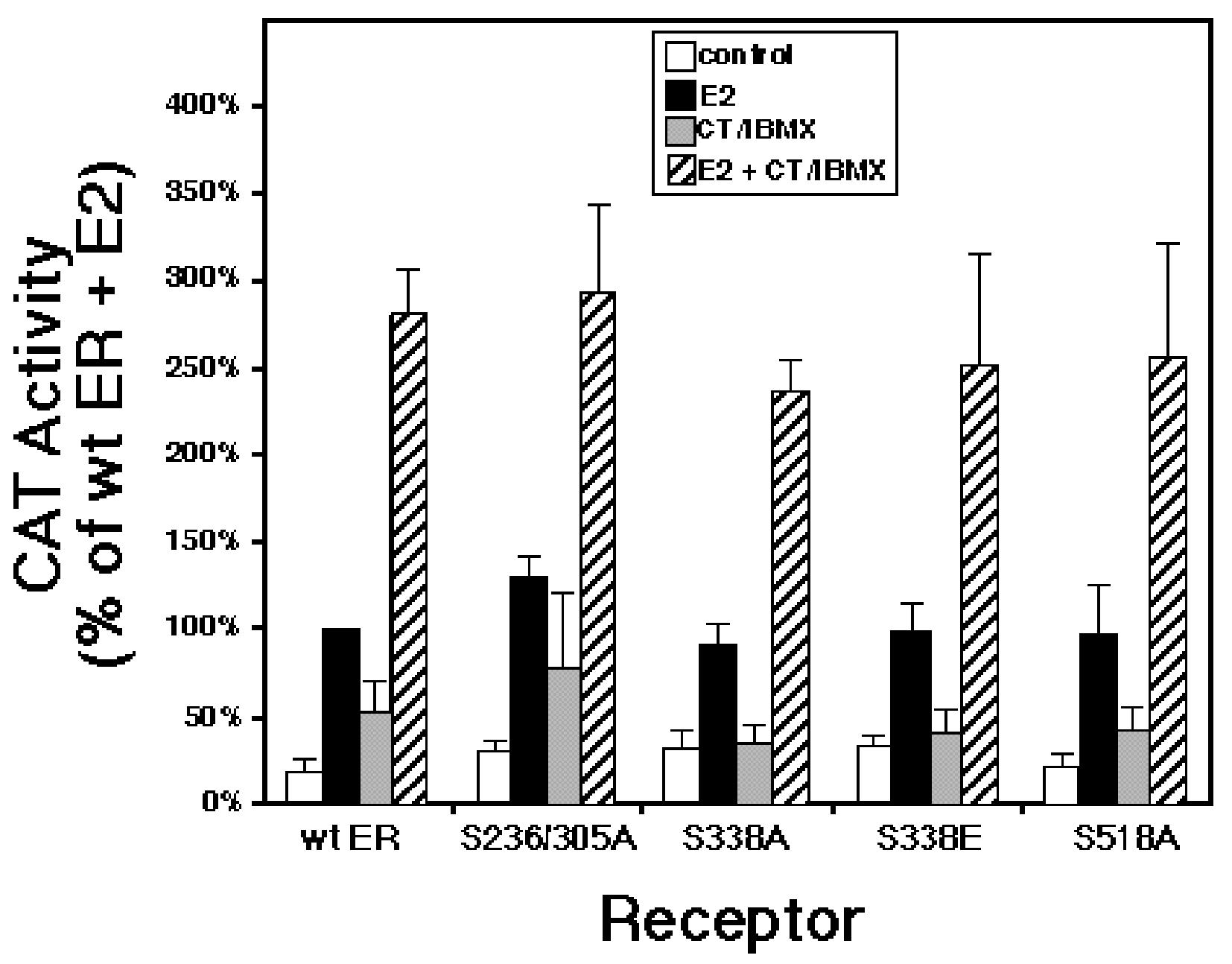

Fig. 1 


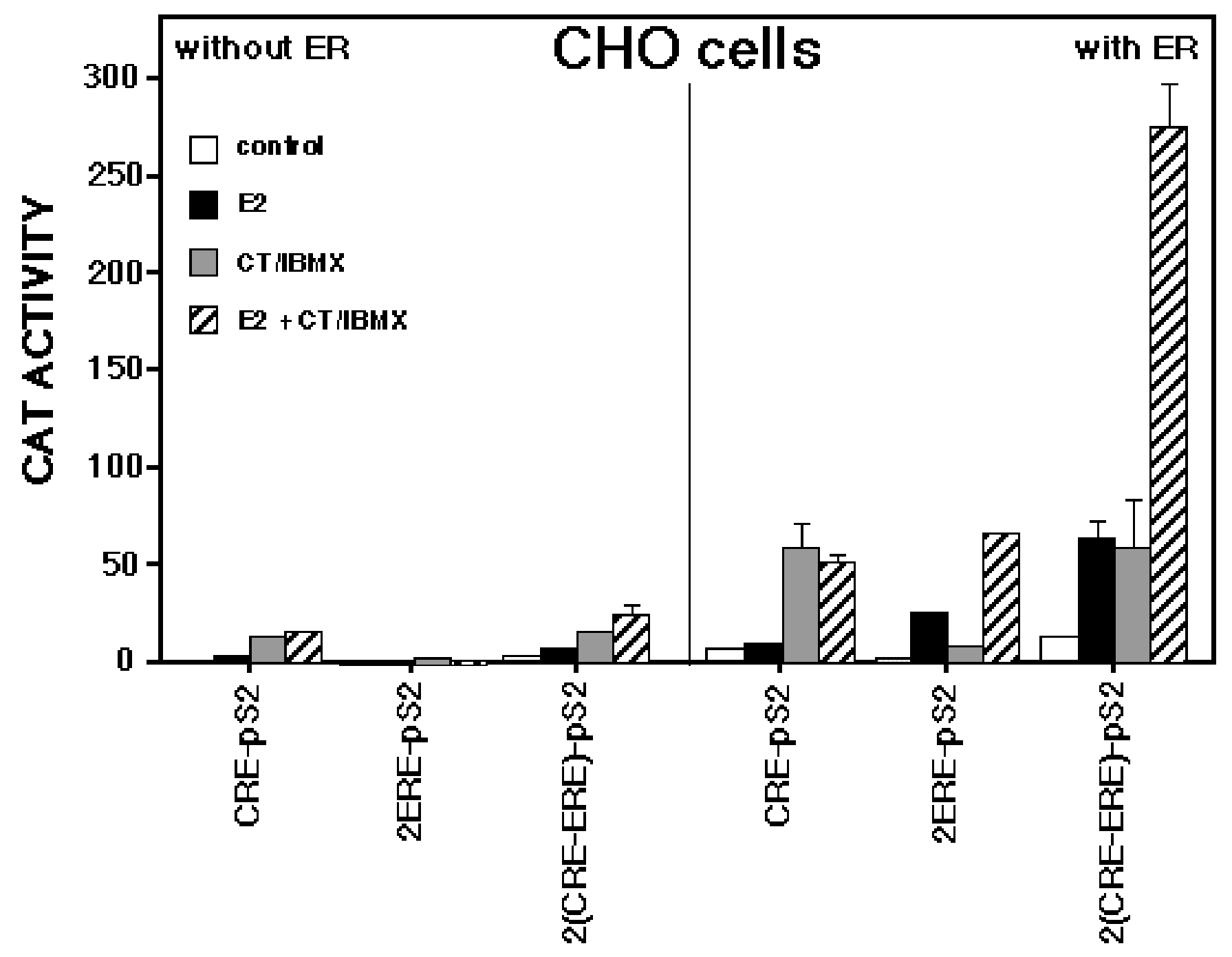

Fig. 2A 


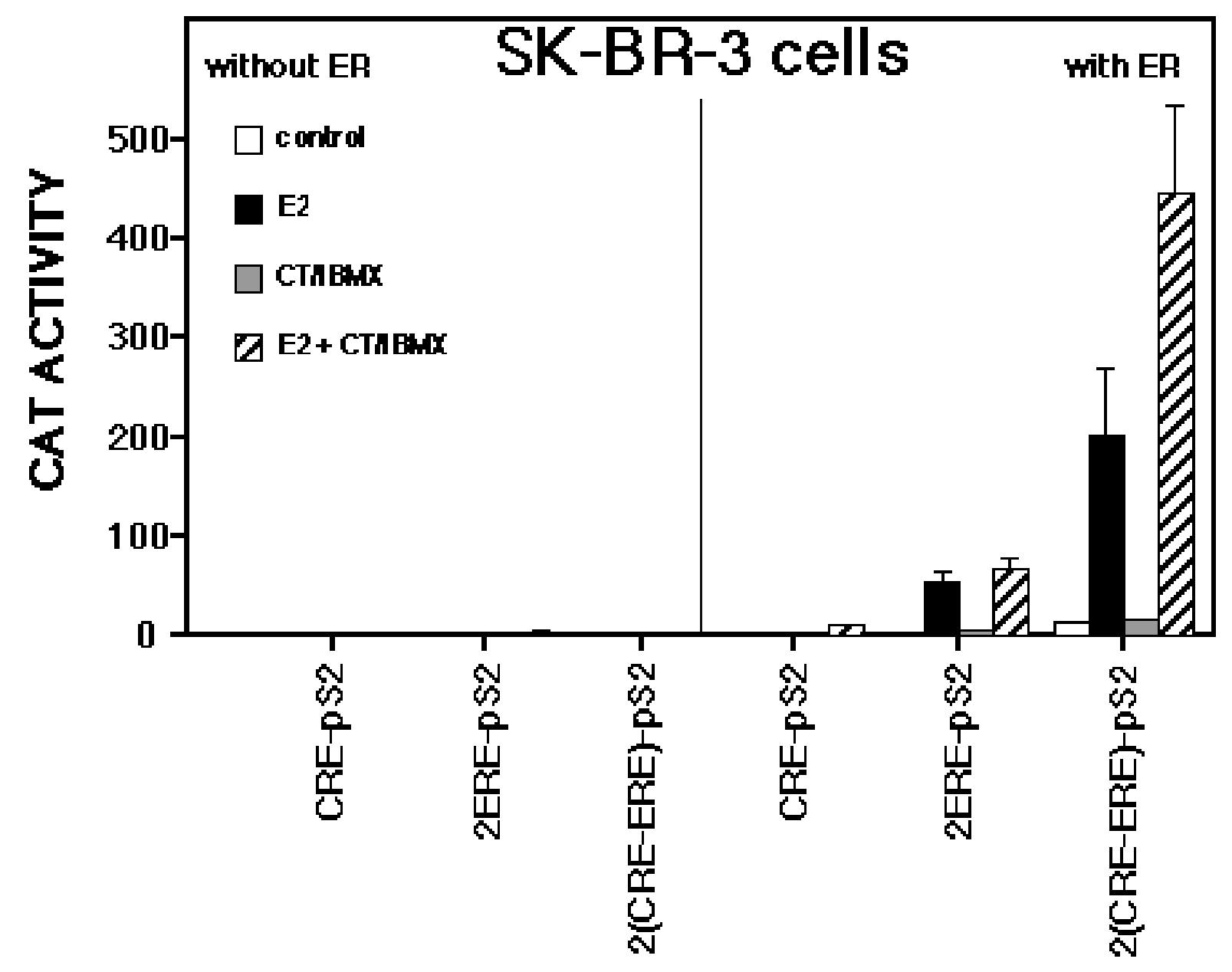

Fig. 2B 

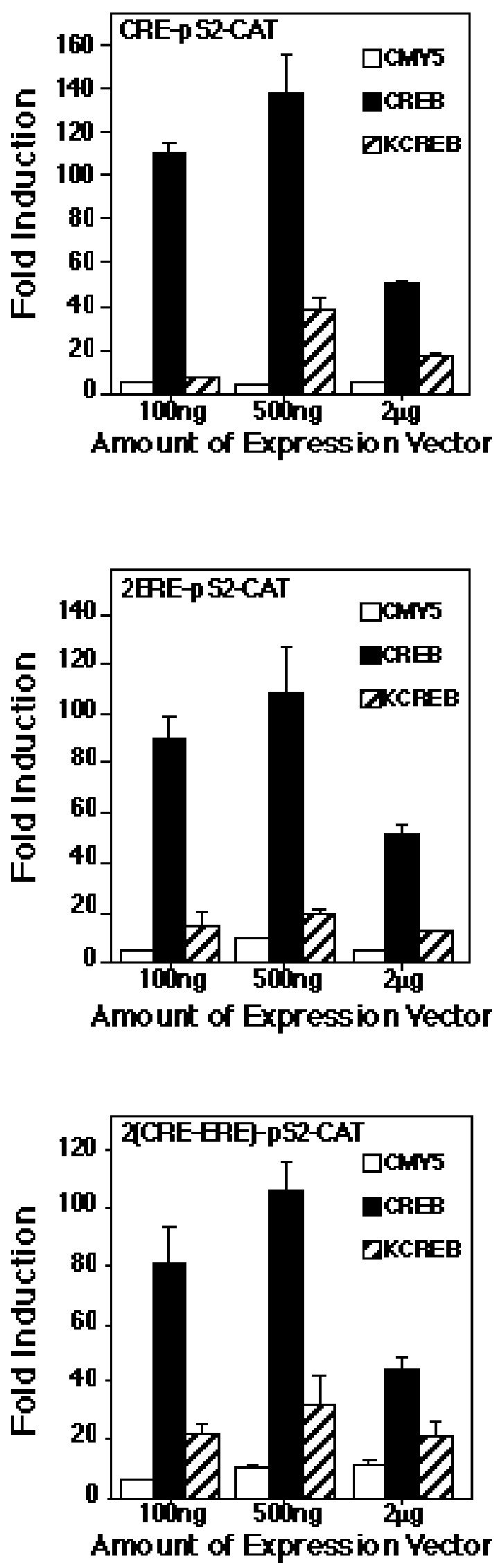

Fig. 3 


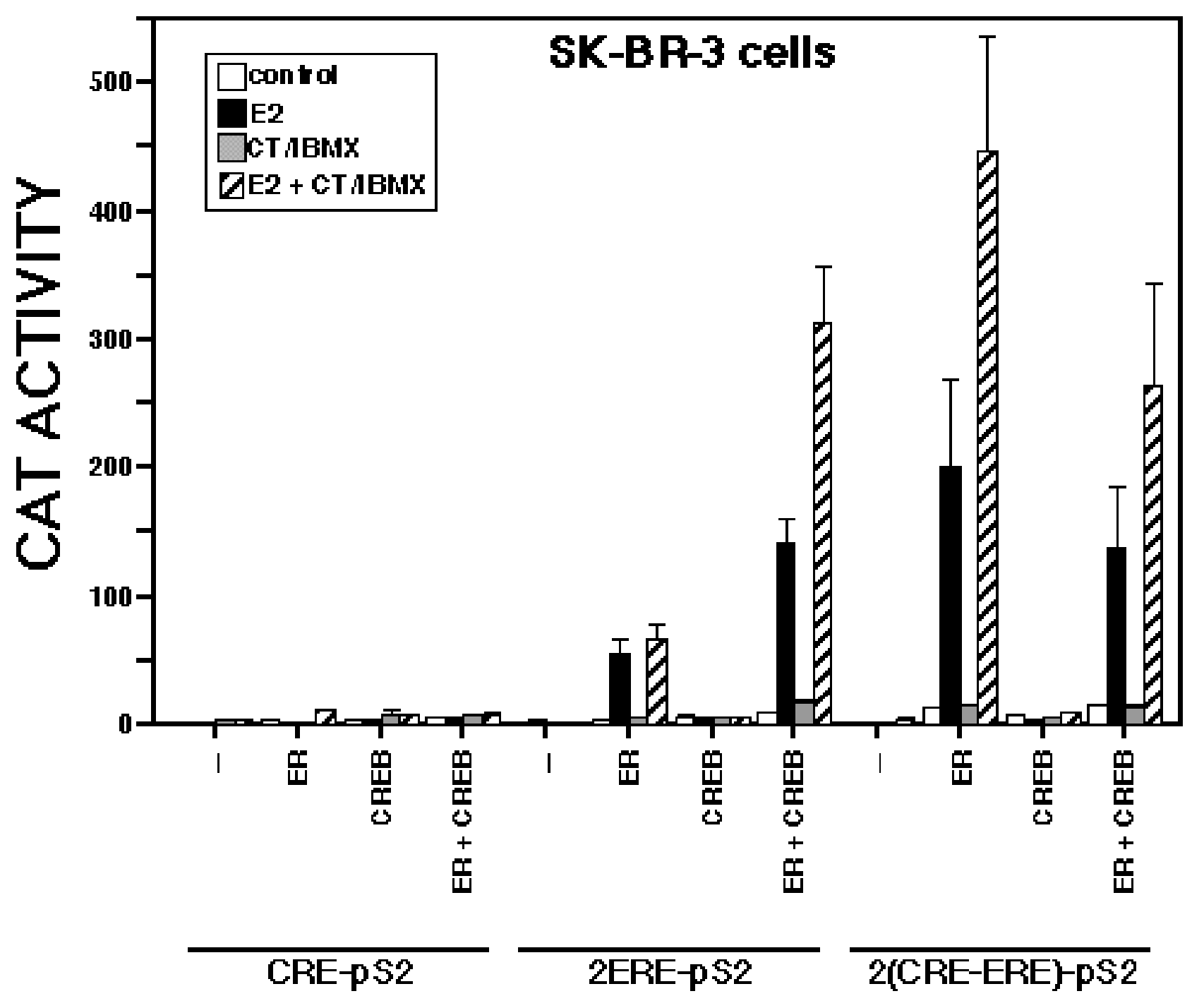

Fig. 4 


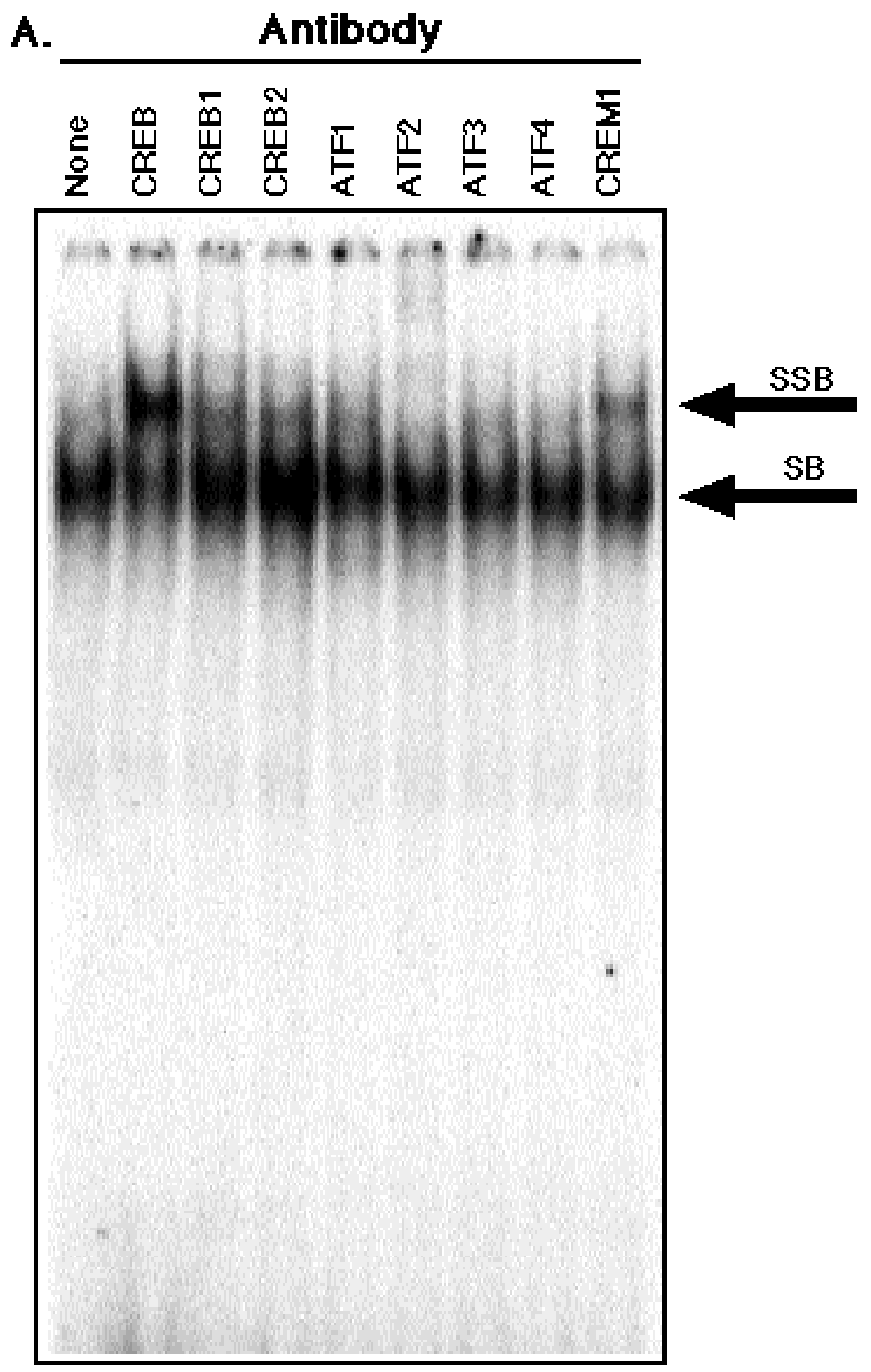

Fig. 5A 


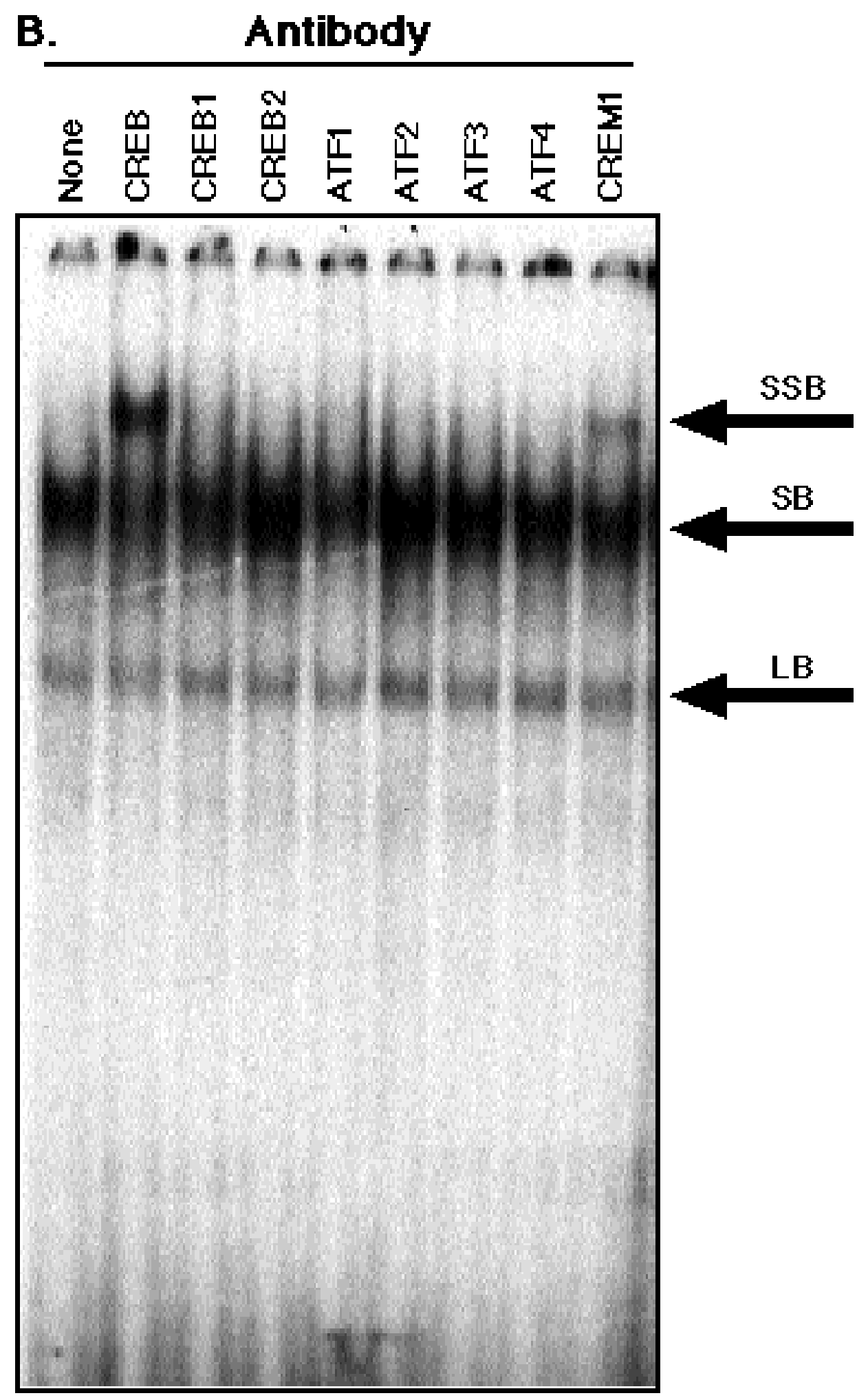

Fig. 5B 


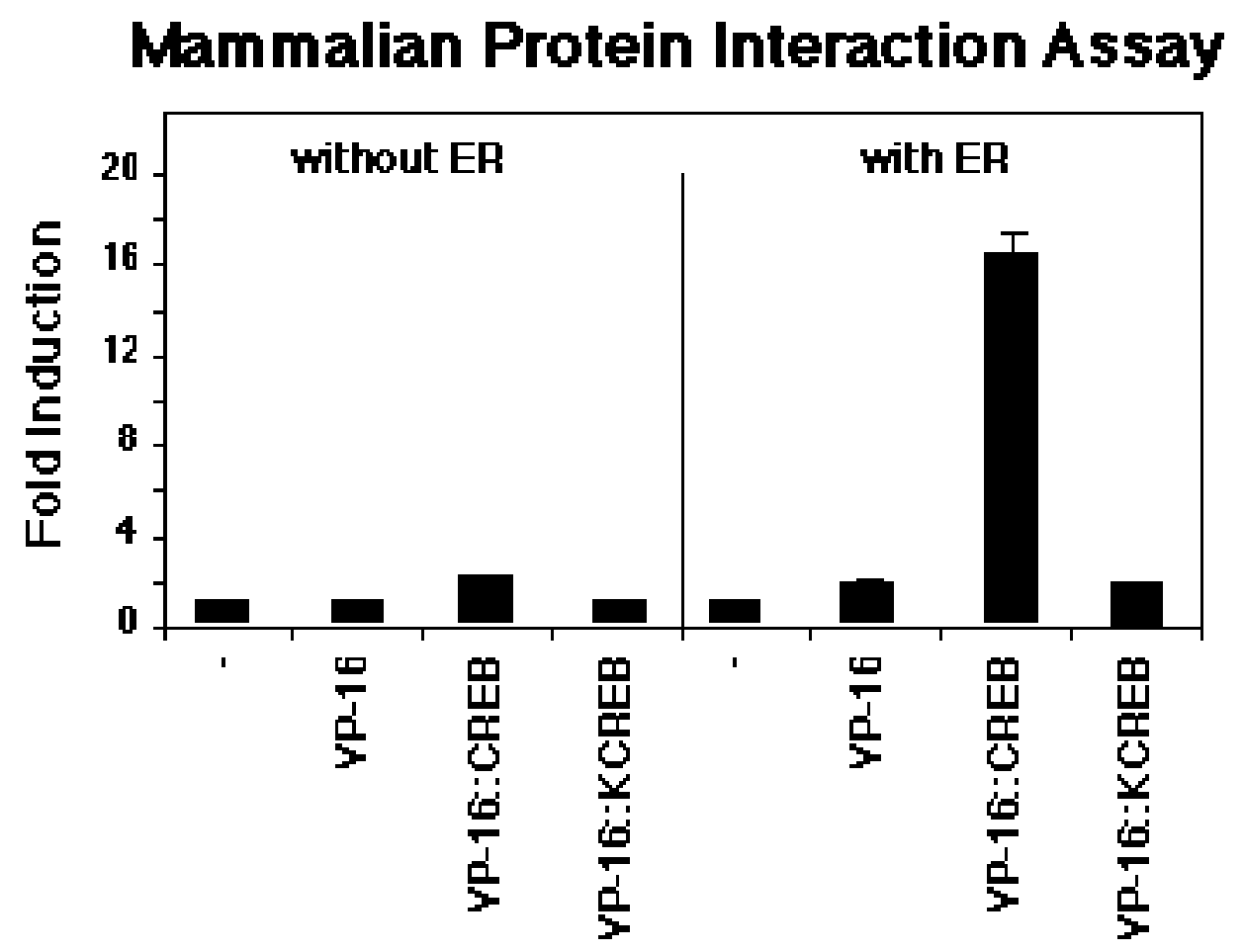

Fig. 6 
A

\section{CHO cells}

$06 \mathrm{ER}$

口 endoge nous CREB

a exogenous CREB

WW $\mathrm{CBP}$
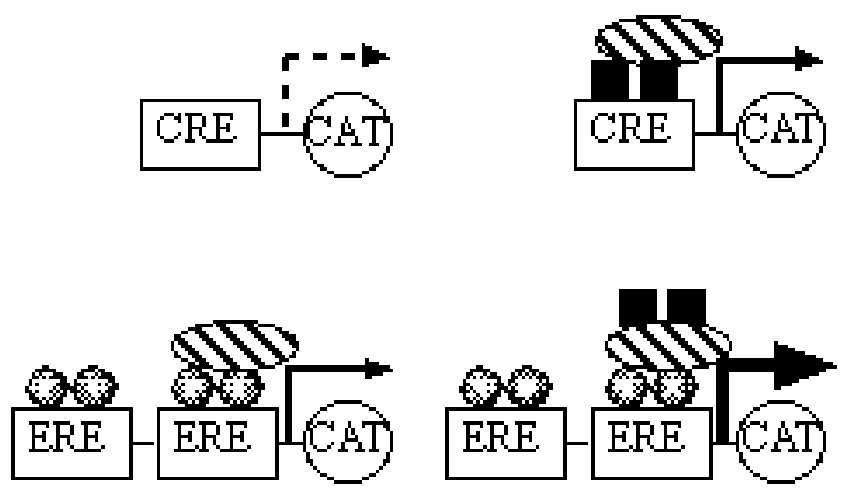

$+\mathrm{CREB}$
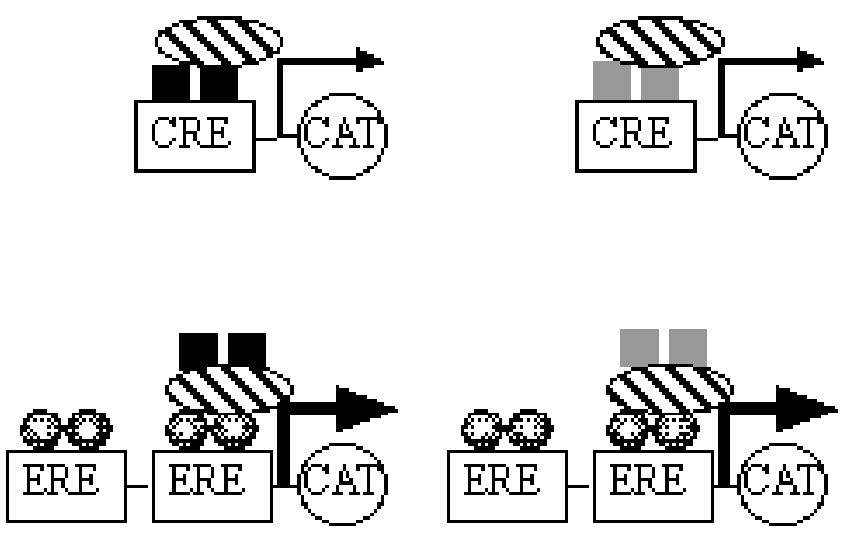

B

SK-BR-3 cells

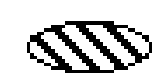

$\mathrm{CRE}: \mathrm{EAT}$

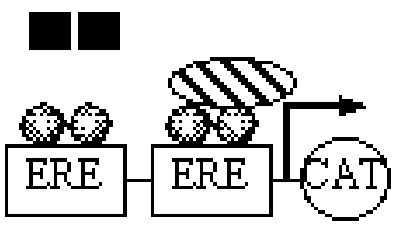

$+\mathrm{CREB}$

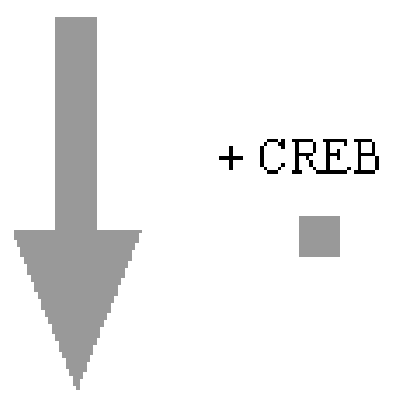

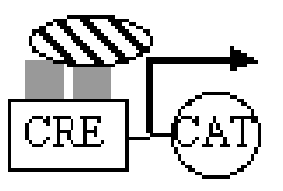

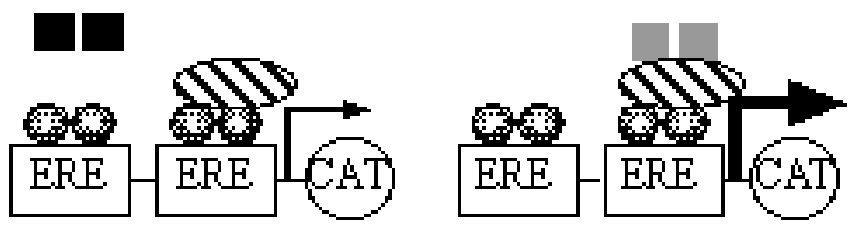

